\title{
One-week administration of hydroxytyrosol to humans does not activate Phase II enzymes
}

\author{
Maria Carmen Crespo a , Joao Tomé-Carneiro ${ }^{a}$, Emma Burgos-Ramos ${ }^{a}$, \\ Viviana Loria Kohen ${ }^{\mathrm{b}}$, Maria Isabel Espinosa ${ }^{\mathrm{b}}$, Jesus Herranz ${ }^{\mathrm{a}}$, Francesco Visioli ${ }^{\mathrm{a}, \mathrm{c}, *}$ \\ a Laboratory of Functional Foods, Madrid Institute for Advanced Studies (IMDEA)-Food, CEI UAM+CSIC, Madrid, Spain \\ b Unidad de Nutrición y Ensayos Clínicos, Plataforma Genyal, IMDEA-Food, CEI UAM+CSIC, Madrid, Spain \\ ${ }^{\mathrm{c}}$ Department of Molecular Medicine, University of Padova, Italy
}

\section{A R T I C L E I N F O}

\section{Article history:}

Received 18 March 2015

Received in revised form 24 March 2015

Accepted 24 March 2015

Available online 30 March 2015

\section{Keywords:}

Hydroxytyrosol

Inflammation

Phase II enzymes

Nrf2

Cardiovascular disease

Mediterranean diet

\begin{abstract}
A B S T R A C T
The notion that (poly)phenols act as direct free radical scavengers is being challenged by mere chemical and biochemical considerations such as bioavailability and intracellular concentrations. An alternative hypothesis that is gaining considerable traction is that (poly)phenols are processed by the body as xenobiotics via the Keap1/Nrf2/ARE signaling axis, leading to the induction of Phase II enzymes. However, there are no solid human data to confirm this interesting supposition. In this study, we tested the activities of hydroxytyrosol (HT) on Phase II enzymes' expression in a double-blind, randomized, placebo-controlled study. We tested two HT doses, i.e. 5 and $25 \mathrm{mg} / \mathrm{d}$, vs. placebo following a Latin square design. We report that HT is well tolerated but does not significantly modify Phase II enzyme expression in peripheral blood mononuclear cells. Moreover, we were unable to record significant effects on a variety of surrogate markers of cardiovascular disease such as lipid profile and inflammation and oxidation markers. Available evidence indicates that the "hormesis hypothesis" that (poly)phenols activate Phase II enzymes requires solid human confirmation that might be provided by future trials.
\end{abstract}

This study is registered at ClinicalTrials.gov (identifier: NCT02273622).

(C) 2015 Elsevier Ltd. All rights reserved.

\section{Introduction}

(Poly)phenols are the products of plants' secondary metabolism and are endowed with several botanical activities [1]. Notable examples include roles in pollination, color, insect repelling, and cellular signal transduction. In addition, since the Zutphen Study [2] (poly)phenol consumption by humans is being consistently associated with better cardiovascular prognosis and chemoprevention. Pharma-nutritionists are trying to explain the molecular mechanisms responsible for the purported healthful activities of (poly)phenols; major emphasis is being placed on their antioxidant actions, which would counteract the noxious effects of reactive oxygen species and free radicals. However, the widespread notion that (poly)phenols act as direct free radical scavengers is challenged by mere chemical and biochemical considerations

* Corresponding author at: IMDEA-Food, CEI UAM+CSIC, Carretera de Cantoblanco 8, 28049 Madrid, Spain. Tel.: +34 912796986; fax: +39 02700426106.

E-mail address: francesco.visioli@imdea.org (F. Visioli). such as bioavailability and intracellular concentrations (namely, as compared with endogenous antioxidants), reaction kinetics, etc. [3].

An alternative hypothesis that is gaining considerable traction is that (poly)phenols are processed by the body as xenobiotics $[3,4]$. Therefore, they stimulate stress-related cell signaling pathways that result in increased expression of genes encoding cytoprotective genes. In particular, Nrf2 (NF-E2-related factor 2) is a transcription factor which binds to the Antioxidant Response Element (ARE) in cells and thus regulates enzymes involved in antioxidant functions or detoxification such as thioredoxin reductase-1 and glutathione peroxidases [3]. According to the hormesis theory, (poly)phenols paradoxically act on the Keap1/Nrf2/ARE signaling axis to produce additive increases in electrophilic signaling that results in the induction of Phase II enzymes and increased nucleophilic substrates, such as glutathione, thioredoxin, and NADPH. In brief, (poly)phenols likely exert indirect rather than direct antioxidant actions. However, there are no solid human data to confirm this interesting supposition. 


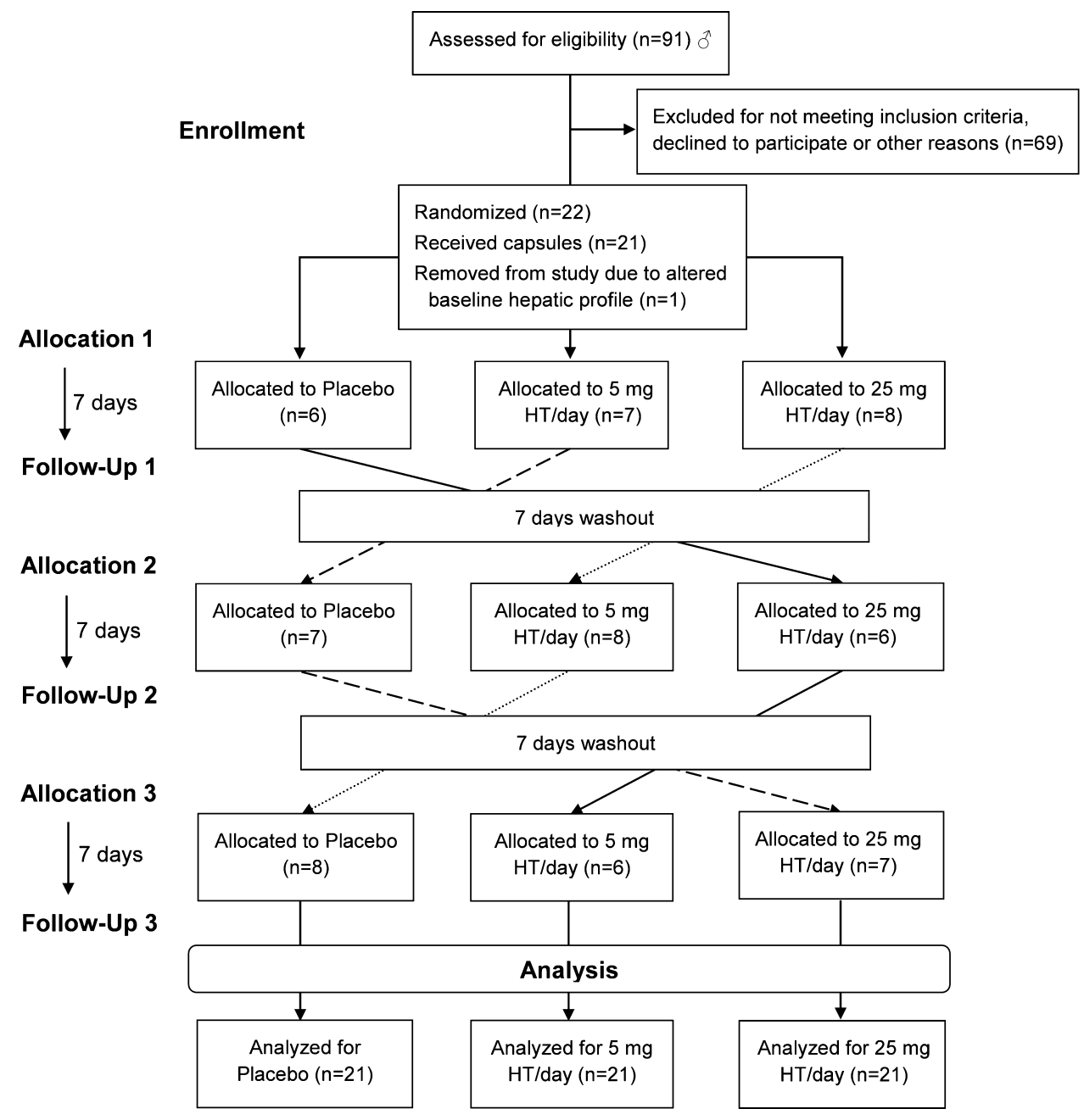

Fig. 1. Study flowchart.

In this study, we tested the activities of hydroxytyrosol (HT) on Phase II enzymes' expression in a double-blind, randomized, placebo-controlled study.

\section{Materials and methods}

\subsection{Subjects and study design}

The study protocol was approved by the local Ethics committee and was fully explained to the participants. Written informed consent was obtained by all subjects prior to starting the trial. This work has been carried out in accordance with The Code of Ethics of the World Medical Association (Declaration of Helsinki) and is registered at ClinicalTrials.gov (identifier: NCT02273622).

This was a double-blind, randomized, placebo-controlled study. We tested two HT doses, i.e. 5 and $25 \mathrm{mg} / \mathrm{d}$ provided via administration of Hytolive ${ }^{\circledR}$ (Genosa, Madrid, Spain), an olive mill waste water (OMWW) extract selectively enriched in HT, i.e. devoid of oleuropein or other HT-containing secoiridoids as assessed by HPLC [5], via anion-exchange chromatography. Twenty-two apparently healthy volunteers were recruited from within the IMDEA-Food Genyal platform database. Inclusion criteria were: age between 20 and 40 years; adequate understanding of the study; willingness to complete the entire treatment. Exclusion criteria were: body mass index $<19$ or $>26$; diagnosis of diabetes mellitus, hypertension, dyslipidemia or other cardiometabolic disorders; impaired cognitive function; diagnosed hepatic, renal, or cardiovascular disease; allergy to olives and their derivatives; pharmacological therapies; and habitual smoking. To our knowledge, there are no previous studies testing the activities of HT on Phase II enzymes' expression in humans. Therefore, we designed a pilot study and we could not calculate power. However, the use of repeated measures increases the power to detect treatment differences in mean levels of the outcome measure over time.

We followed a Latin square design: after one-week washout, i.e. olive-free diet, subjects were randomly assigned to either the placebo (maltodextrin), $5 \mathrm{mg} / \mathrm{d} \mathrm{HT}$, or $25 \mathrm{mg} / \mathrm{d}$ HT group (Fig. 1). The complete capsule composition is described in Supplementary Table 1. Administration of each treatment was carried out for one week, followed by a one-week washout after which treatments were switched. Volunteers were instructed not to consume any olive-based products or medication throughout the study and were instructed to write down any occurrences (consumption of prohibited foods, medication intake, etc.) and intolerance issues (diarrhea, acidity, nausea, abdominal distension, or halitosis) in questionnaires. Capsules were provided in bottles labeled A, B, or C and their contents were unknown to both the volunteers and the nurse who administered the bottles. Compliance was assessed by capsule count.

Blood samples were drawn and anthropometric data (height, weight, body mass index (BMI), bioelectric impedance analysis (BIA)) and vital constants (systolic (SBP) and diastolic blood pressure (DBP), and heart rate) were monitored at each visit. Morning urine was also collected at each time point. 


\subsection{Biochemical analyses}

Triacylglycerol (TG), total (TC), low-density (LDL-c), and highdensity (HDL-c) cholesterol concentrations were measured by routine laboratory (Laboratorio CQS, Madrid, Spain, which follows the UNE-ISO 15189:2007 directives) methods. Urea, creatinine, hepatic enzymes: glutamyl oxaloacetic transaminase (GOT), glutamic-pyruvatetransaminase (GPT) and gamma glutamyltransferase (GGT), bilirubin, and alkaline phosphatase (AP) were also measured by routine laboratory methods. The concentration of oxidized LDL was measured by sandwich enzyme-linked immunosorbent assay (ELISA) by using the monoclonal antibody mAb-4E6 (Mercodia AB, Sweden).

Urinary thromboxane $B_{2}$ and total isoprostanes were quantified by competitive ELISA (Enzo Biochem, Inc., NY, USA and Oxford Biomedical Research, MI, USA, respectively).

\subsection{Multiplex bead immunoassay}

In a subset of samples, plasma concentrations of Interleukin (IL)-6, IL-8, IL-10, IL-17, monocyte chemoattractant protein 1 (MCP1); Tumor necrosis factor alpha (TNF $\alpha$ ), and vascular endothelial growth factor (VEGF) were measured using a magnetic bead-based immunoassay (MAGPIX-Luminex) kit from Millipore, following the manufacturer's instructions. A minimum of 50 beads per parameter were analyzed by the MAGPIX-Luminex system. Raw data (median fluorescence intensity, MFI) were analyzed with the XPONENT software 4.1.

\subsection{Isolation of peripheral blood mononuclear cells (PBMCs)}

Subjects were instructed to fast overnight before each blood collection. Blood samples were collected between 8 and 10 AM to minimize circadian variations. Blood samples were collected in heparinized tubes (BD Vacutainer, Franklin Lakes, NJ, USA) at each visit, processed within $2 \mathrm{~h}$ after extraction and used to PBMCs. Isolation was carried out under sterile conditions to avoid monocytes activation. Whole blood was diluted (1:1) with phosphate buffer solution (PBS) and centrifuged by density gradient with Histopaque-1077 (Sigma-Aldrich, Madrid, Spain) according to the manufacturer's instructions. After collection, PBMCs were washed twice with PBS, homogenized in Qiazol (Qiagen, Madrid, Spain) and stored at $-80^{\circ} \mathrm{C}$ prior to RNA extraction.

\subsection{RNA extraction and microarray samples preparation}

Total RNA was extracted and purified from homogenized PBMCs with miRNeasy minikit (Qiagen, Valencia, CA, USA) following the manufacturer's protocol. Recovered RNA's concentration and integrity were verified using a Nanodrop ND-1000 spectrophotometer (Nanodrop TechnologyR, Cambridge, UK) and an Agilent 2100 Bioanalyzer (Agilent, Madrid, Spain).

\subsection{Gene expression analysis}

After DNAse I treatment (Invitrogen, Madrid, Spain), reverse transcription was performed with miScript ${ }^{\circledR}$ II Reverse Transcription kit (Qiagen, Germantown, MD) according to the manufacturer's guidelines. RT-qPCR reactions were performed in 384-well plates and gene expression was determined using the 7900HT Real-Time PCR System (Life Technologies, Spain). Reactions were performed with $5 \mu \mathrm{L}$ of miScript SYBR ${ }^{\circledR}$ Green qPCR Master Mix (Qiagen, Madrid, Spain). Cycling conditions were $15 \mathrm{~min}$ at $95^{\circ} \mathrm{C}$ for one cycle, then 40 cycles at $94^{\circ} \mathrm{C}$ for $15 \mathrm{~s}, 58^{\circ} \mathrm{C}$ for $30 \mathrm{~s}, 70^{\circ} \mathrm{C}$ for $30 \mathrm{~s}$, for each gene. The dissociation stage was analyzed at $95^{\circ} \mathrm{C}$ for $15 \mathrm{~s}$, followed by one cycle at $60^{\circ} \mathrm{C}$ for $15 \mathrm{~s}$, and $95^{\circ} \mathrm{C}$ for $15 \mathrm{~s}$. Gene expression analysis was carried out for twenty Phase II enzymes (primers can be found in Supplementary Table 2). Three potential reference genes-GAPDH, HPLPO, and ACTB-were tested in order to select the most stable to be used in target gene's normalization, which according to Normfinder was the latter. Reactions were run in triplicate and relative expression of Phase II enzymes was calculated by the comparative $\mathrm{Ct}$ method and presented as $2^{-\Delta \Delta \mathrm{Ct}}$.

\subsection{Statistical analyses}

Continuous descriptive variables were expressed as mean \pm SEM. Two-way repeated measures ANOVA was used to evaluate the effects of time $\left(t_{1}\right.$ and $\left.t_{2}\right)$, treatment $(A, B, C)$ and the time $\times$ treatment interaction. A Bonferroni correction for multiple analyses was applied and models were adjusted for age and sequence $(\mathrm{ABC} / \mathrm{CAB} / \mathrm{BCA})$ as covariates. All statistical analyses were considered as bilateral and significance was set at $p<0.05$. Data were analyzed with $\mathrm{R}$ Statistical Software version 3.1.1 (www.r-project.org).

\section{Results}

One volunteer was excluded from the study because he exhibited abnormal basal bilirubin concentrations (Fig. 1); attrition rate was, therefore, zero. Both 5 and $25 \mathrm{mg}$ HT doses were well-tolerated and no adverse effect was reported.

No differences in anthropometric variables, such as weight or body mass index, were recorded and no significant variations in vital signs such as blood pressure were noted either (Table 1 ).

Table 1

Anthropometric parameters and vital signs.

\begin{tabular}{|c|c|c|c|c|c|c|c|c|c|}
\hline \multirow[t]{2}{*}{ Measured parameters } & \multicolumn{2}{|l|}{ A } & \multicolumn{2}{|l|}{ B } & \multicolumn{2}{|l|}{$\mathrm{C}$} & \multicolumn{3}{|c|}{ Effect $(p)^{*}$} \\
\hline & Initial & Final & Initial & Final & Initial & Final & Time & Treatment & Time $\times$ treatment \\
\hline Weight (kg) & $73.31(1.58)$ & $73.1(1.61)$ & $73.1(1.58)$ & 72.85 (1.57) & 73.07 (1.62) & $72.73(1.64)$ & $0.002^{*}$ & 0.989 & 0.833 \\
\hline B.M.I $\left(\mathrm{kg} / \mathrm{m}^{2}\right)$ & $23.69(0.41)$ & $23.62(0.42)$ & $23.62(0.43)$ & $23.55(0.43)$ & $23.61(0.44)$ & $23.49(0.45)$ & $0.002^{*}$ & 0.984 & 0.721 \\
\hline FM (\%) & $19.99(1.16)$ & $20.01(1.23)$ & $20.1(1.23)$ & $20.02(1.24)$ & $19.87(1.3)$ & $19.82(1.25)$ & 0.787 & 0.991 & 0.944 \\
\hline MM (\%) & $39.81(0.71)$ & $39.72(0.77)$ & $39.69(0.77)$ & $39.67(0.77)$ & $39.78(0.81)$ & $39.82(0.78)$ & 0.805 & 0.993 & 0.821 \\
\hline AVF & $5.9(0.42)$ & $5.95(0.43)$ & $5.86(0.44)$ & $5.76(0.44)$ & $5.86(0.44)$ & $5.76(0.45)$ & 0.263 & 0.973 & 0.287 \\
\hline $\mathrm{SBP}(\mathrm{mmHg})$ & $130(2.35)$ & $131.1(1.98)$ & $129.62(2.84)$ & $131.19(2.18)$ & $130.14(2.47)$ & $128.71(2.17)$ & 0.681 & 0.920 & 0.424 \\
\hline $\mathrm{DBP}(\mathrm{mmHg})$ & $70.1(1.51)$ & $72.48(1.48)$ & $71.57(1.61)$ & $71.71(1.46)$ & $70.29(1.21)$ & $71.24(1.76)$ & 0.1622 & 0.878 & 0.531 \\
\hline HR (Beat/min) & $60.19(3.96)$ & $69(2.91)$ & $64.05(2.15)$ & $67.76(2.5)$ & $63.38(2.01)$ & $66.1(2.75)$ & $0.0013^{*}$ & 0.893 & 0.214 \\
\hline
\end{tabular}

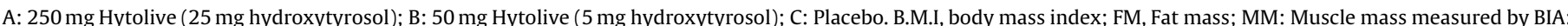

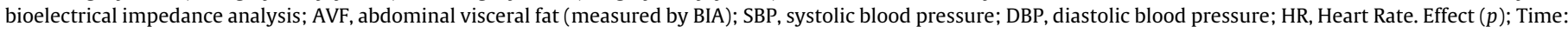

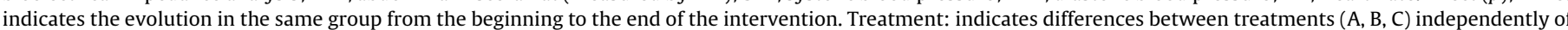

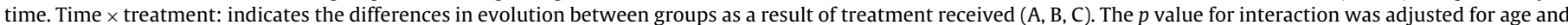
sequence of consumption as covariates. Data are means (SEM).

${ }^{*} p<0.05$. 
Table 2

Biochemical parameters evaluated in each of the visits.

\begin{tabular}{|c|c|c|c|c|c|c|c|c|c|}
\hline \multirow[t]{2}{*}{ Measured parameters } & \multicolumn{2}{|l|}{ A } & \multicolumn{2}{|l|}{ B } & \multicolumn{2}{|l|}{ C } & \multicolumn{3}{|c|}{ Effect $(p)^{*}$} \\
\hline & Initial & Final & Initial & Final & Initial & Final & Time & Treatment & Time $\times$ treatment \\
\hline $\mathrm{TC}(\mathrm{mg} / \mathrm{dl})$ & $169.3(6.54)$ & $169.7(6.51)$ & $168.6(6.39)$ & $173.9(6.8)$ & $170.8(6.77)$ & $169.4(5.97)$ & 0.388 & 0.975 & 0.258 \\
\hline $\mathrm{HDL}(\mathrm{mg} / \mathrm{dl})$ & $52.83(2.57)$ & $51.04(2.06)$ & $52.17(2.66)$ & $52.14(2.44)$ & $51.84(2.26)$ & $50.87(2.48)$ & 0.229 & 0.960 & 0.644 \\
\hline $\mathrm{LDL}(\mathrm{mg} / \mathrm{dl})$ & $99.47(5.47)$ & $103.0(5.41)$ & $101.3(5.47)$ & $106.2(5.7)$ & $102.5(5.78)$ & $103.7(5.17)$ & $0.031^{*}$ & 0.923 & 0.559 \\
\hline $\mathrm{TG}(\mathrm{mg} / \mathrm{dl})$ & $85.1(7.26)$ & $78.24(6.15)$ & $75.81(4.2)$ & $77.6(6.57)$ & $82(8.05)$ & $74.6(4.96)$ & 0.163 & 0.793 & 0.371 \\
\hline hs-CRP (mg/dl) & $0.07(0.02)$ & $0.16(0.06)$ & $0.09(0.02)$ & $0.05(0.01)$ & $0.09(0.02)$ & $0.05(0.01)$ & 0.47 & 0.117 & $0.049^{*}$ \\
\hline $\mathrm{TXB}_{2}(\mathrm{ng} / \mathrm{ml})$ & $1.55(0.2)$ & $1.71(0.14)$ & $1.97(0.26)$ & $1.72(0.16)$ & $2.17(0.18)$ & $1.83(0.3)$ & 0.253 & 0.316 & 0.222 \\
\hline $\mathrm{TXB}_{2} /$ Creat $(\mu \mathrm{g} / \mathrm{g})$ & $0.87(0.06)$ & $0.86(0.05)$ & $1.03(0.10)$ & $0.9(0.06)$ & $1.01(0.06)$ & $0.94(0.08)$ & 0.097 & 0.373 & 0.502 \\
\hline LDL-ox $(\mathrm{U} / \mathrm{l})$ & $42.6(2.32)$ & $41.34(2.04)$ & $42.19(2.31)$ & $43.95(2.56)$ & $41.28(2.84)$ & $41.34(2.31)$ & 0.849 & 0.814 & 0.445 \\
\hline Isop (ng/ml) & $2.99(0.34)$ & $3.59(0.41)$ & $3.71(0.41)$ & $3.78(0.42)$ & $4.78(0.63)$ & $3.38(0.56)$ & 0.477 & 0.298 & $0.052^{*}$ \\
\hline Isop/Creat $(\mu \mathrm{g} / \mathrm{g})$ & $1.64(0.08)$ & $1.75(0.1)$ & $1.92(0.13)$ & $2.05(0.17)$ & $2.42(0.33)$ & $1.74(0.14)$ & 0.257 & 0.128 & $0.020^{*}$ \\
\hline GOT/AAT (UI/l) & $19.71(1.26)$ & $19.95(1.18)$ & $18.05(0.79)$ & $18.9(0.96)$ & $19.52(0.77)$ & $19.33(1.09)$ & 0.525 & 0.520 & 0.662 \\
\hline GPT/AT (UI/l) & $19.33(1.9)$ & 19.67 (1.79) & $18.38(1.49)$ & $18.24(1.38)$ & $20.0(1.6)$ & $18.62(1.17)$ & 0.458 & 0.744 & 0.403 \\
\hline GGT (UI/l) & 21.07 (1.99) & $21.48(2.44)$ & $22.38(2.27)$ & $21.89(2.0)$ & $21.69(2.07)$ & $20.66(1.78)$ & 0.260 & 0.909 & 0.196 \\
\hline $\mathrm{TB}(\mathrm{mg} / \mathrm{dl})$ & $1.1(0.08)$ & $1.16(0.1)$ & $1.16(0.11)$ & $1.12(0.09)$ & $1.06(0.08)$ & $1.21(0.1)$ & 0.148 & 0.994 & 0.143 \\
\hline $\mathrm{AP}(\mathrm{UI} / \mathrm{l})$ & $55.95(2.92)$ & $64.33(3.89)$ & $58.86(3.31)$ & $62.86(3.23)$ & $57.76(3.6)$ & $61.76(3.3)$ & $0.001^{*}$ & 0.967 & 0.204 \\
\hline Urine creatinin $(\mathrm{mg} / \mathrm{dl})$ & $177.5(16.9)$ & $202.2(15.9)$ & $190.2(14.5)$ & $193.6(14.0)$ & $215.7(14.8)$ & $184.8(14.1)$ & 0.910 & 0.814 & $0.024^{*}$ \\
\hline
\end{tabular}

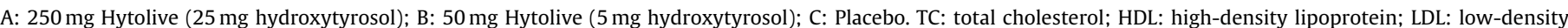

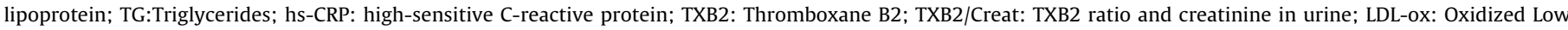

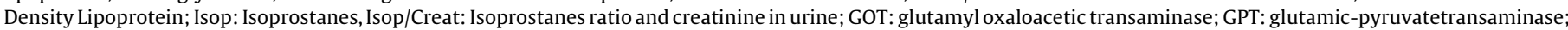

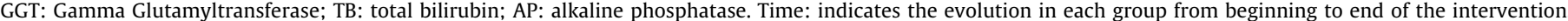

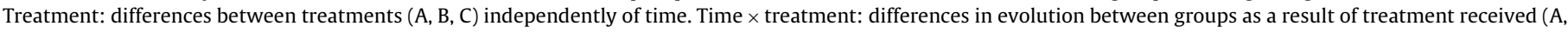
$B, C)$. Age and sequence of consumption were used as covariates. Data are means (SEM).

$$
\text { * } p<0.05 \text {. }
$$

Table 3

Cytokine levels after the consumption of the study products (A and C).

\begin{tabular}{|c|c|c|c|c|c|c|c|}
\hline \multirow[t]{2}{*}{ Measured parameters } & \multicolumn{2}{|l|}{ A } & \multicolumn{2}{|l|}{$\mathrm{C}$} & \multicolumn{3}{|c|}{ Effect $(p)^{*}$} \\
\hline & Initial & Final & Initial & Final & Time & Treatment & Time $\times$ treatment \\
\hline IL-10 (pg/ml) & $2.22(0.97)$ & $1.36(0.41)$ & $0.79(0.16)$ & $1.71(0.97)$ & 0.96 & 0.46 & 0.17 \\
\hline IL-17 (pg/ml) & $30.7(10.2)$ & $29.2(8.18)$ & $14.3(2.61)$ & $15.3(3.98)$ & 0.91 & 0.12 & 0.58 \\
\hline IL-6 (pg/ml) & $10.6(4.99)$ & $11.5(5.73)$ & $6.20(2.80)$ & $5.20(1.51)$ & 0.96 & 0.18 & 0.45 \\
\hline IL-8 (pg/ml) & $30.4(9.57)$ & $28.1(8.56)$ & $14.3(4.43)$ & $21.4(9.92)$ & 0.50 & 0.31 & 0.20 \\
\hline MCP-1 (pg/ml) & $486(54.0)$ & $472(54.1)$ & $412(37.0)$ & $446(43.5)$ & 0.52 & 0.36 & 0.14 \\
\hline TNF- $\alpha(\mathrm{pg} / \mathrm{ml})$ & $8.99(1.02)$ & $8.31(0.88)$ & $7.37(0.64)$ & $6.74(0.54)$ & $0.04^{*}$ & 0.12 & 0.92 \\
\hline $\operatorname{VEGF}(\mathrm{pg} / \mathrm{ml})$ & $605(164)$ & $682(182)$ & $577(110)$ & $497(98.2)$ & 0.98 & 0.53 & 0.10 \\
\hline
\end{tabular}

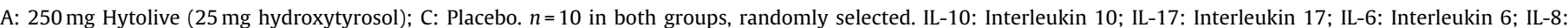
Interleukin 8; MCP-1: Monocyte chemoattractant protein 1; TNF- $\alpha$ : Tumor necrosis factor alpha; VEGF: Vascular endothelial growth factor. Data are means (SEM).

$p<0.05$.

Table 2 reports the plasma concentrations of selected surrogate markers of cardiovascular disease and hepatic enzymes. We only recorded significant time $\times$ treatment interactions for isoprostanes (markers of oxidation) and hs-CRP (marker of inflammation). Of note, hepatic function enzymes, which are - alas - rarely measured in nutraceutical studies, were not modified by either treatment.

In a subset of samples, namely those who received the highest HT dose vs. controls, we also quantified an array of plasma cytokines (Table 3 ) and did not find any significant variation induced by HT.

Phase II enzyme expression in PBMCs is reported in Table 4. We only documented a time effect on GSTO1 and GSTP1 levels, whereas all other genes were unaffected by the provision of HT.

\section{Discussion}

The notion that (poly)phenols trigger stress signaling mediated by Nrf-2 and Phase II enzymes is, nowadays, predominant over that of their plain antioxidant actions $[3,6]$. However, this hypothesis has never been confirmed in humans (to the best of our knowledge), with the exception of Hofmann et al. [7], who reported modest yet significant increases of glutathione $S$-transferase P1 (hGSTP1) protein expression in leukocytes of healthy volunteers given fruit juice. In brief, while biochemical verification of $\mathrm{Nrf}-2$ mediated hormesis is strong, human evidence is scant or non-existent.

In this paper we report that HT, administered at two different doses in a Latin-square design study was well tolerated (as shown by the unaltered levels of hepatic enzymes, Table 2), but does not significantly modify Phase II enzyme expression in PBMCs. Moreover, we were unable to record significant effects on a variety of surrogate markers of cardiovascular disease such as lipid profile and inflammation and oxidation markers. Actually, we computed a non-significant increase in plasma hs-CRP and in urinary isoprostanes concentrations. The latter finding is in agreement with that of Leger el al. [8] and in disagreement with Visioli at al [9], who, however, administered extra virgin olive oils rather than HT. Because these differences were non-significant it is difficult to comment on their true physiological relevance; however, these data reiterate the concept that (poly)phenols and other minor food components exert biological effects whose nature and extent depend on the matrix, i.e. as part of food or provided as pharmanutritional formulations.

We chose hydroxytyrosol (the foremost component of extra virgin olive oil [10]) as paradigmatic example of (poly)phenols because (1) it is the only phenolic molecule that received a European Food Safety Authority (EFSA) health claim [11]; (2) it has been shown to increase Nrf-2 expression in vitro [12,13] albeit at nonphysiological doses [14]; (3) a "xeno-hormesis" postulation has also been proposed to explain the salubrious actions of extra virgin olive oil phenolics [15]; and (4) a previous human study with an olive mill waste water (OMWW) preparation reported increased glutathione levels short-term in human volunteers [16]. A glutathione effect was also recorded in rats [17] and a short-term 
Table 4

Gene expression of Phase II enzymes after the consumption of the study products (A, B and C).

\begin{tabular}{|c|c|c|c|c|c|c|c|c|c|c|}
\hline \multirow[t]{2}{*}{ Phase II enzymes } & \multirow[t]{2}{*}{ Initial } & \multicolumn{6}{|c|}{ Final } & \multicolumn{3}{|c|}{ Effect $(p)^{*}$} \\
\hline & & $\mathrm{A}$ & & B & & C & & Time & Treatment & Time $\times$ treatment \\
\hline NQO1 & 1 & 1.11 & $(0.11)$ & 0.81 & $(0.07)$ & 1.50 & $(0.61)$ & 0.79 & 0.58 & 0.35 \\
\hline NQO2 & 1 & 1.79 & $(0.87)$ & 1.04 & $(0.08)$ & 1.05 & $(0.09)$ & 0.74 & 0.66 & 0.95 \\
\hline GSTA1 & 1 & 1.28 & $(0.32)$ & 1.32 & $(0.24)$ & 1.01 & $(0.17)$ & 0.38 & 0.93 & 0.45 \\
\hline GSTA4 & 1 & 1.01 & $(0.10)$ & 1.11 & $(0.09)$ & 1.10 & $(0.13)$ & 0.73 & 0.79 & 0.58 \\
\hline GSTK1 & 1 & 1.27 & $(0.35)$ & 0.99 & $(0.07)$ & 1.03 & $(0.12)$ & 0.87 & 0.42 & 0.96 \\
\hline GSTM1 & 1 & 1.22 & $(0.13)$ & 0.89 & $(0.06)$ & 1.19 & $(0.24)$ & 0.40 & 0.89 & 0.16 \\
\hline GSTM2 & 1 & 1.73 & $(0.37)$ & 1.20 & $(0.15)$ & 1.54 & $(0.44)$ & 0.12 & 0.92 & 0.97 \\
\hline GSTM3 & 1 & 1.16 & $(0.17)$ & 1.15 & $(0.12)$ & 1.06 & $(0.15)$ & 0.96 & 0.92 & 0.46 \\
\hline GSTM4 & 1 & 1.22 & $(0.17)$ & 0.97 & $(0.07)$ & 1.19 & $(0.29)$ & 0.63 & 0.89 & 0.29 \\
\hline GSTM5 & 1 & 1.39 & (0.39) & 1.07 & $(0.15)$ & 1.18 & $(0.24)$ & 0.36 & 0.88 & 0.95 \\
\hline GSTO1 & 1 & 0.90 & $(0.09)$ & 1.18 & $(0.15)$ & 0.90 & $(0.08)$ & $0.03^{*}$ & 0.65 & 0.25 \\
\hline GSTO2 & 1 & 0.97 & $(0.08)$ & 0.93 & $(0.08)$ & 1.11 & $(0.11)$ & 0.30 & 0.82 & 0.69 \\
\hline GSTP1 & 1 & 1.24 & (0.09) & 1.28 & $(0.16)$ & 1.46 & $(0.25)$ & $0.02^{*}$ & 0.85 & 0.99 \\
\hline GSTT1 & 1 & 0.94 & $(0.07)$ & 1.06 & $(0.09)$ & 1.22 & $(0.21)$ & 0.73 & 0.84 & 0.56 \\
\hline GSTT2 & 1 & 1.58 & $(0.26)$ & 1.22 & $(0.15)$ & 1.08 & $(0.14)$ & 0.50 & 0.59 & 0.29 \\
\hline HNMT & 1 & 0.97 & $(0.08)$ & 1.02 & $(0.10)$ & 1.02 & $(0.08)$ & 0.56 & 0.94 & 0.63 \\
\hline INMT & 1 & 1.00 & $(0.13)$ & 1.13 & $(0.15)$ & 1.03 & $(0.15)$ & 0.09 & 0.54 & 0.52 \\
\hline MGST1 & 1 & 1.06 & $(0.13)$ & 1.19 & $(0.13)$ & 1.05 & $(0.10)$ & 0.98 & 0.70 & 0.22 \\
\hline MGST2 & 1 & 1.01 & $(0.07)$ & 1.02 & $(0.08)$ & 1.06 & $(0.13)$ & 0.31 & 0.89 & 0.55 \\
\hline MGST3 & 1 & 0.90 & $(0.08)$ & 1.13 & $(0.08)$ & 1.05 & $(0.11)$ & 0.16 & 0.92 & 0.17 \\
\hline
\end{tabular}

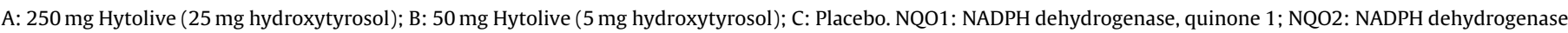

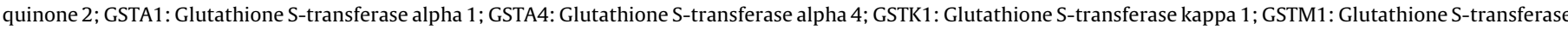

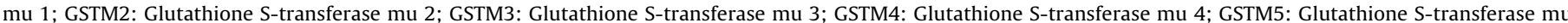

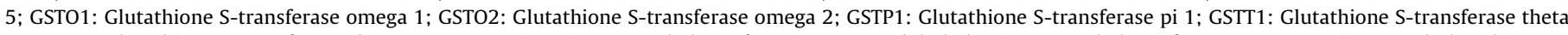

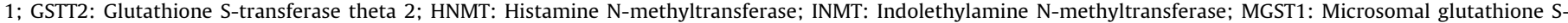
transferase 1; MGST2: Microsomal glutathione S-transferase 2; MGST3: Microsomal glutathione S-transferase 3. Data are fold change means (SEM).

$p<0.05$.

increase in skeletal muscle glutathione concentrations after exercise was reported by Bast and Haenen, who administered an HT-rich olive extract (providing $200 \mathrm{mg}$ of HT) to human volunteers [18]. Finally, a nutrigenomic study carried out in mice reported that HT - in nutritionally relevant amounts - is able to positively modulate the glutathione-driven antioxidant enzymatic machinery in adipose tissue [19].

Of note, Visioli et al. [16] previously suggested that part of the purported healthful activities of HT might be governed by the antioxidant response element (ARE)-mediated increase in Phase II enzyme expression. Therefore, we undertook the current study to verify this premise in a controlled setting. Indeed, we also wanted to verify in humans the now popular notion that describes (poly)phenols as activators of the stress response pathways. We used PMBCs because they are easily accessible, express many genes previously believed to be restricted to non-blood tissues responding to macro- or micro-environment alterations in organs, and have been shown to be suitable for nutritional studies, reflecting specific effects of diets or nutrients [20-22].

To date, there are two human studies that have been performed with OMWW and one where the authors administered pure HT $[8,23,24]$. The former reported anti-thrombogenicity [8,23], while the latter only addressed absorption and disposition and did not inform on biochemical data [24].

Several hypotheses can be formulated to explain the discrepancy between our current results and those obtained with high-polyphenol extra virgin olive oil or those of Visioli et al. [16], namely in terms of oxLDL [25] and platelet aggregation [8,23] or oxidation and inflammatory markers [9]. First and foremost, we administered two doses of HT, i.e. 5 and $25 \mathrm{mg} / \mathrm{d}$ for one week. Higher doses might produce the hypothesized effects and are supposed to be safe. However, it is noteworthy that the EFSA healthclaim [11] relates to $5 \mathrm{mg} / \mathrm{d}$ of HT and HT-containing phenols as protectors of LDL from oxidation. From a practical viewpoint this implies that formulations that provide HT amounts higher than this dose might have to deal with some regulatory issues, even though the safety profile of HT is excellent [26-28] as confirmed by the current study (Table 2). As a matter of fact, Visioli and Galli administered $50 \mathrm{mg}$ of HT and recorded effects on $\mathrm{TXB}_{2}$ production by serum short term, i.e. $1 \mathrm{~h}$ after intake [23]. These data were confirmed by Leger et al. [8], who provided five type I diabetic patients with $25 \mathrm{mg}$ of HT the first day and $12.5 \mathrm{mg}$ /day the following 3 days. A $46 \%$ decrease in the serum $\mathrm{TXB}_{2}$ production after blood clotting at $\mathrm{T}(4 \mathrm{~d})$ was recorded [8]. Whether high doses of (poly)phenols trigger other short-term effects such as Phase II enzyme expression remains to be verified in humans. Also, the activation of Phase II enzymes might be organ-specific [29]; whether sustained hepatic Phase II enzymes activation occurs in humans would be very difficult to ascertain for obvious ethical and practical reasons.

Another important issue that the nutraceutical world is trying to address is that of healthy volunteers vs. patients [30]. Clinical trials of nutraceuticals, supplements, or functional foods in patients clash with obvious ethical guidelines; as a result, these preparations are often added to established, top-quality therapy, therefore making it difficult to ascertain their real contribution. One notable example is that of omega 3 fatty acids $[31,32]$. Our cohort of healthy volunteers exhibited normal-range concentrations of surrogate markers of cardiovascular disease at baseline: further reduction of such concentrations might be difficult to achieve. Conversely, HT might speculatively be beneficially used as medical food [33], i.e. as adjunct therapy of cardiovascular and other inflammationbased diseases [34] or to metabolic syndrome patients, pending confirmation by appropriate clinical trials [35].

Finally, it is worth reiterating that nutraceuticals and functional foods must exert modest (and often undetectable based on current methodologies) physiological effects which, however, could produce remarkable health activities if taking place long-term [36]. Indeed, epidemiological evidence of healthful activities is strong and corroborates the "sub-clinical, lifetime exposure" proposition.

In conclusion, the physiological activities of HT are - as of today limited to inhibition of $\mathrm{TXB}_{2}$ production by serum, leading to a possible prevention of thrombotic and micro-thrombotic processes. Most important, the "hormesis hypothesis" that (poly)phenols 
activate Phase II enzymes requires solid human confirmation that might be provided by future trials.

\section{Acknowledgements}

This study was supported by a grant from the Spanish Ministerio de Ciencia e Innovacion (AGL2011-28995) and co-funded by the "Marie Curie Amarout European Programme" We thank Genosa I+D (Madrid, Spain) for kindly supplying Hytolive ${ }^{\circledR}$ and placebo. European FEDER Funds. Programa de actividades en tecnologias ALIBIRD-CM S2013/ABU-2728 de la Comunidad de Madrid.

\section{Appendix A. Supplementary data}

Supplementary data associated with this article can be found, in the online version, at http://dx.doi.org/10.1016/j.phrs.2015.03.018.

\section{References}

[1] D. Del Rio, A. Rodriguez-Mateos, J.P. Spencer, M. Tognolini, G. Borges, A. Crozier, Dietary (poly)phenolics in human health: structures, bioavailability, and evidence of protective effects against chronic diseases, Antioxid. Redox Signal. 18 (2013) 1818-1892.

[2] M.G. Hertog, E.J. Feskens, P.C. Hollman, M.B. Katan, D. Kromhout, Dietary antioxidant flavonoids and risk of coronary heart disease: the Zutphen elderly study, Lancet 342 (1993) 1007-1011.

[3] H.J. Forman, K.J. Davies, F. Ursini, How do nutritional antioxidants really work: nucleophilic tone and para-hormesis versus free radical scavenging in vivo, Free Radic. Biol. Med. 66 (2014) 24-35.

[4] G. Chiva-Blanch, F. Visioli, Polyphenols and health: moving beyond antioxidants, J. Berry Res. 2 (2012) 63-71

[5] S. Schaffer, M. Podstawa, F. Visioli, P. Bogani, W.E. Muller, G.P. Eckert, Hydroxytyrosol-rich olive mill wastewater extract protects brain cells in vitro and ex vivo, J. Agric. Food Chem. 55 (2007) 5043-5049.

[6] F. Visioli, C.A. De La Lastra, C. Andres-Lacueva, M. Aviram, C. Calhau, A. Cassano, M. D’Archivio, A. Faria, G. Fave, V. Fogliano, R. Llorach, P. Vitaglione, M. Zoratti, M. Edeas, Polyphenols and human health: a prospectus, Crit. Rev. Food Sci. Nutr. 51 (2011) 524-546.

[7] T. Hofmann, U. Liegibel, P. Winterhalter, A. Bub, G. Rechkemmer, B.L. PoolZobel, Intervention with polyphenol-rich fruit juices results in an elevation of glutathione s-transferase p1 (hgstp1) protein expression in human leucocytes of healthy volunteers, Mol. Nutr. Food Res. 50 (2006) 1191-1200.

[8] C.L. Leger, M.A. Carbonneau, F. Michel, E. Mas, L. Monnier, J.P. Cristol, B. Descomps, A thromboxane effect of a hydroxytyrosol-rich olive oil wastewater extract in patients with uncomplicated type i diabetes, Eur. J. Clin. Nutr. 59 (2005) 727-730.

[9] F. Visioli, D. Caruso, C. Galli, S. Viappiani, G. Galli, A. Sala, Olive oils rich in natural catecholic phenols decrease isoprostane excretion in humans, Biochem. Biophys. Res. Commun. 278 (2000) 797-799.

[10] M.I. Covas, V. Ruiz-Gutiérrez, R. de la Torre, A. Kafatos, R. Lamuela-Raventós, J. Osada, R.W. Owen, F. Visioli, Minor components of olive oil: evidence to date of health benefits in humans, Nutr. Rev. 64 (2006) S20-S30.

[11] EFSA Panel on Dietetic Products, Scientific opinion on the substantiation of health claims related to polyphenols in olive and protection of ldl particles from oxidative damage (id 1333, 1638, 1639, 1696, 2865), maintenance of normal blood hdl cholesterol concentrations (id 1639), maintenance of normal blood pressure (id 3781), "anti-inflammatory properties" (id 1882), "contributes to the upper respiratory tract health" (id 3468), "can help to maintain a normal function of gastrointestinal tract" (3779), and "contributes to body defences against external agents" (id 3467) pursuant to article 13(1) of regulation (ec) no 1924/2006, EFSA J. 9 (2009) 2033-2058.

[12] X. Zou, Z. Feng, Y. Li, Y. Wang, K. Wertz, P. Weber, Y. Fu, J. Liu, Stimulation of gsh synthesis to prevent oxidative stress-induced apoptosis by hydroxytyrosol in human retinal pigment epithelial cells: activation of Nrf2 and jnk-p62/sqstm1 pathways, J. Nutr. Biochem. 23 (2012) 994-1006.

[13] H. Zrelli, M. Matsuoka, S. Kitazaki, M. Araki, M. Kusunoki, M. Zarrouk, H. Miyazaki, Hydroxytyrosol induces proliferation and cytoprotection against oxidative injury in vascular endothelial cells: role of Nrf2 activation and ho-1 induction, J. Agric. Food Chem. 59 (2011) 4473-4482.
[14] S. Schaffer, B. Halliwell, Comment on hydroxytyrosol induces proliferation and cytoprotection against oxidative injury in vascular endothelial cells: role of Nrf2 activation and ho-1 induction, J. Agric. Food Chem. 59 (2011) 10770-10771.

[15] J.A. Menendez, J. Joven, G. Aragones, E. Barrajon-Catalan, R. Beltran-Debon, I. Borras-Linares, J. Camps, B. Corominas-Faja, S. Cufi, S. Fernandez-Arroyo, A. Garcia-Heredia, A. Hernandez-Aguilera, M. Herranz-Lopez, C. Jimenez-Sanchez, E. Lopez-Bonet, J. Lozano-Sanchez, F. Luciano-Mateo, B. Martin-Castillo, V. Martin-Paredero, A. Perez-Sanchez, C. Oliveras-Ferraros, M. Riera-Borrull, E. Rodriguez-Gallego, R. Quirantes-Pine, A. Rull, L. Tomas-Menor, A. VazquezMartin, C. Alonso-Villaverde, V. Micol, A. Segura-Carretero, Xenohormetic and anti-aging activity of secoiridoid polyphenols present in extra virgin olive oil: a new family of gerosuppressant agents, Cell Cycle 12 (2013) 555-578.

[16] F. Visioli, R. Wolfram, D. Richard, M.I. Abdullah, R. Crea, Olive phenolics increase glutathione levels in healthy volunteers, J. Agric. Food Chem. 57 (2009) 1793-1796.

[17] A. Kotronoulas, N. Pizarro, A. Serra, P. Robledo, J. Joglar, L. Rubio, A. Hernaez C. Tormos, M.J. Motilva, M. Fito, M.I. Covas, R. Sola, M. Farre, G. Saez, R. de la Torre, Dose-dependent metabolic disposition of hydroxytyrosol and formation of mercapturates in rats, Pharmacol. Res. 77 (2013) 47-56.

[18] A. Bast, G.R.M.M. Haenen, Nutritional antioxidants. It is time to categorise, in: M. Lamprecht (Ed.), Antioxidants in Sport Nutrition, CRC Press, Boca Raton, FL, USA, 2015, pp. 17-37.

[19] E. Giordano, A. Davalos, F. Visioli, Chronic hydroxytyrosol feeding modulates glutathione-mediated oxido-reduction pathways in adipose tissue: a nutrigenomic study, Nutr. Metab. Cardiovasc. Dis. 24 (2014) 1144-1150.

[20] C.C. Liew, J. Ma, H.C. Tang, R. Zheng, A.A. Dempsey, The peripheral blood transcriptome dynamically reflects system wide biology: a potential diagnostic tool, J. Lab. Clin. Med. 147 (2006) 126-132.

[21] M. Bouwens, O. van de Rest, N. Dellschaft, M.G. Bromhaar, L.C. de Groot, J.M. Geleijnse, M. Muller, L.A. Afman, Fish-oil supplementation induces antiinflammatory gene expression profiles in human blood mononuclear cells, Am. J. Clin. Nutr. 90 (2009) 415-424.

[22] J. Tome-Carneiro, M. Larrosa, M.J. Yanez-Gascon, A. Davalos, J. Gil-Zamorano, M. Gonzalvez, F.J. Garcia-Almagro, J.A. Ruiz Ros, F.A. Tomas-Barberan, J.C. Espin, M.T. Garcia-Conesa, One-year supplementation with a grape extract containing resveratrol modulates inflammatory-related micrornas and cytokines expression in peripheral blood mononuclear cells of type 2 diabetes and hypertensive patients with coronary artery disease, Pharmacol. Res. 72 (2013) 69-82.

[23] F. Visioli, C. Galli, Olives and their production waste products as sources of bioactive compounds, Curr. Top. Nutr. Res. 1 (2003) 85-88.

[24] M. Gonzalez-Santiago, J. Fonolla, E. Lopez-Huertas, Human absorption of a supplement containing purified hydroxytyrosol, a natural antioxidant from olive oil, and evidence for its transient association with low-density lipoproteins, Pharmacol. Res. 61 (2010) 364-370.

[25] M.I. Covas, K. Nyyssonen, H.E. Poulsen, J. Kaikkonen, H.J. Zunft, H. Kiesewetter A. Gaddi, R. de la Torre, J. Mursu, H. Baumler, S. Nascetti, J.T. Salonen, M. Fito, J. Virtanen, J. Marrugat, The effect of polyphenols in olive oil on heart disease risk factors: a randomized trial, Ann. Intern. Med. 145 (2006) 333-341.

[26] D. Auñon-Calles, L. Canut, F. Visioli, Toxicological evaluation of pure hydroxytyrosol, Food Chem. Toxicol. 55 (2013) 498-504.

[27] D. Auňon-Calles, E. Giordano, S. Bohnenberger, F. Visioli, Hydroxytyrosol is not genotoxic in vitro, Pharmacol. Res. 74 (2013) 87-93.

[28] H. Babich, F. Visioli, In vitro cytotoxicity to human cells in culture of some phenolics from olive oil, Farmaco 58 (2003) 403-407.

[29] T.R. Balstad, H. Carlsen, M.C. Myhrstad, M. Kolberg, H. Reiersen, L. Gilen, K. Ebihara, I. Paur, R. Blomhoff, Coffee, broccoli and spices are strong inducers of electrophile response element-dependent transcription in vitro and in vivo studies in electrophile response element transgenic mice, Mol. Nutr. Food Res. 55 (2011) 185-197.

[30] S. Mahabir, Methodological challenges conducting epidemiological research on nutraceuticals in health and disease, PharmaNutrition 2 (2014) 120-125.

[31] C. von Schacky, Omega-3 fatty acids in cardiovascular disease-an uphill battle, Prostaglandins Leukot. Essent. Fatty Acids 92 (2015) 41-47.

[32] F. Visioli, Cover story: what is wrong with omega 3 fatty acids? PharmaNutrition 2 (2014) A1.

[33] T.C. Weenen, E.S. Pronker, H.R. Commandeur, E. Claassen, Patenting in the European medical nutrition industry: trends, opportunities and strategies, PharmaNutrition 1 (2013) 13-21.

[34] E.J.B. Ruijters, G.R.M.M. Haenen, A.R. Weseler, A. Bast, The anti-inflammatory efficacy of dexamethasone is protected by (-)-epicatechin, PharmaNutrition 2 (2014) 47-52.

[35] F. Visioli, Nutritional support in the pharmacological treatment of metabolic syndrome, Eur. J. Pharmacol. 668 (Suppl. 1) (2011) S43-S49.

[36] F. Visioli, Can experimental pharmacology be always applied to human nutrition? Int. J. Food Sci. Nutr. 63 (Suppl. 1) (2012) 10-13. 